Neville Edward Parker, Consultant Forensic Psychiatrist, Melbourne, Australia

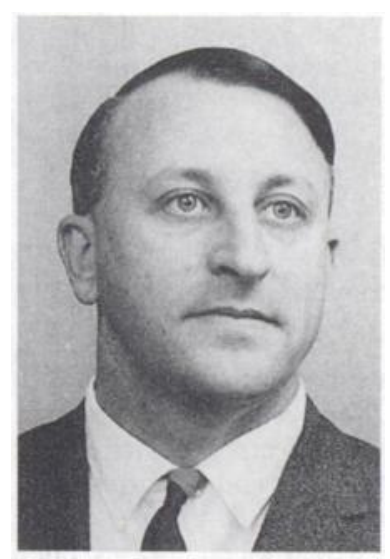

Neville Parker died suddenly, aged 64 , on 22 December 1992 while holidaying with his family in Queensland. His untimely death ended too soon a distinguished career in forensic psychiatry and a productive academic and professional life.

Neville graduated in medicine from Queensland University in 1951, and after post-graduate psychiatric training in Melbourne, returned to

consultant practice in Brisbane. It was at this time that he developed his abiding interest in Huntington's Disease, which led to a Nuffield Fellowship to pursue further study at the Maudsley Hospital, London. On his return he obtained a Doctorate of Medicine (Qld) in 1966 for clinical research in psychiatry and genetics. He was active in the Australian Medical Association and played a considerable part in the establishment of the Australian and New Zealand College of Psychiatrists, serving for some years as both a Queensland Councillor and a member of the Board of Censors. He was Chairman of the Queensland Branch of the RANZCP in 1970 and a frequent guest lecturer, both in Australia and overseas. His interest was, however, increasingly turning to medico-legal matters, and he moved to Melbourne in 1977 where he quickly established himself in the front rank of Australian forensic psychiatry. He was a Foundation Fellow of the Royal College of Psychiatrists.

As before, Neville Parker continued in Victoria to teach forensic psychiatry at both under-graduate and post-graduate levels, while also contributing many papers on topics ranging from the evaluation of crimes of violence to malingering. His overall input to psychiatric literature, exceeding some 50 papers, embraced his early research into genetics and later forensic and social issues.

He was largely instrumental in the establishment in 1985 of 'The Forensic Study Group of the RANZCP' which succeeded the former Association of Private Psychiatrists (Victoria). This group met on a monthly basis in discussion of contemporary forensic issues, with Neville Parker often providing a stimulating and dynamic input. His contributions to this particular field of intellectual and practical activity will be profoundly missed.
He was active both as a consultant in private practice, and as an adviser to the State Government of Victoria on medico-legal and social matters, including the notorious "Garry David Case" ( $A N Z$ Journal of Psychiatry, 1991). His direct and pragmatic approach often led to controversy, but he never departed from his sincerely held expressions of opinion on basic issues.

Neville Parker was a person of singular integrity, both in his professional and private life. He exercised considerable influence on generations of students at both the academic level and by personal professional precept. He was a sincere, frank, and forthright individual in his views, who displayed a great sense of humour and compassion. He was devoted to his wife Joyce and family of seven adult children and nine grandchildren.

The loss of Neville Parker, personally and professionally to the field of human endeavour, can never be adequately measured.

DENIS O'Brien

DAVID BARNES

\section{Howard Phillips Rome, Emeritus Professor, School of Medicine, University of Minnesota, Rochester, Minnesota, USA}

Howard Rome, an internationally acclaimed psychiatrist, died in October 1992 at his home in Rochester, Minnesota, at the age of 81 .

Rome was born in Philadelphia, Pennsylvania, and graduated in medicine at the Temple University School of Medicine, Philadelphia, where he was later to receive an honorary doctorate in science. In July 1947 he began his long and illustrious association with the Mayo Clinic where he served as Head of Psychiatry from 1952 to 1963 and was elected President of the medical staff in 1963.

Rome was past President of the World Psychiatric Association, the Inter-American Council of Psychiatric Associations, the American Psychiatric Association, and the Minnesota Psychiatric Society of which he was a founding member. In addition, he was a fellow of the American College of Psychiatry. During World War II he served as a Commander in the US Navy.

In his time, Rome's contribution to international psychiatry was acknowledged by the award of honours from foreign psychiatric bodies including our own College which elected him to the Honorary Fellowship in 1988.

Rome was a prolific contributor to the psychiatric literature. He served on the editorial boards of many psychiatric publications and was himself editor of Psychiatric Annals. 